University of Rhode Island

DigitalCommons@URI

Open Access Master's Theses

1983

\title{
A Critical Analysis of the Design Features Supported by the Systems with ADA
}

Sunil Agarwal

University of Rhode Island

Follow this and additional works at: https://digitalcommons.uri.edu/theses

\section{Recommended Citation}

Agarwal, Sunil, "A Critical Analysis of the Design Features Supported by the Systems with ADA" (1983). Open Access Master's Theses. Paper 925.

https://digitalcommons.uri.edu/theses/925

This Thesis is brought to you for free and open access by DigitalCommons@URI. It has been accepted for inclusion in Open Access Master's Theses by an authorized administrator of DigitalCommons@URI. For more information, please contact digitalcommons-group@uri.edu. 


\title{
A CRItical ahalisis of
}

THE DESIGN FEATORES SUPPORTED BY

THE SISTEHS UTTH ADA

BY

SOMIL AGAREAL

\begin{abstract}
A THESIS SUBEITTED IN PABTIAL FULFILLHENT OF THE REQUIREABUTS FOR THE DEGBEE OF MASTER OF SCIENCE

IN

COMPOTER SCIBNCE
\end{abstract}

OUIVERSTTY OF RHODE ISLAWD

1983 


\section{MASTER OF SCIEHCE THESIS}

OF

SUII AGARWAL

Approved:

Thes is Committee

Major Professor

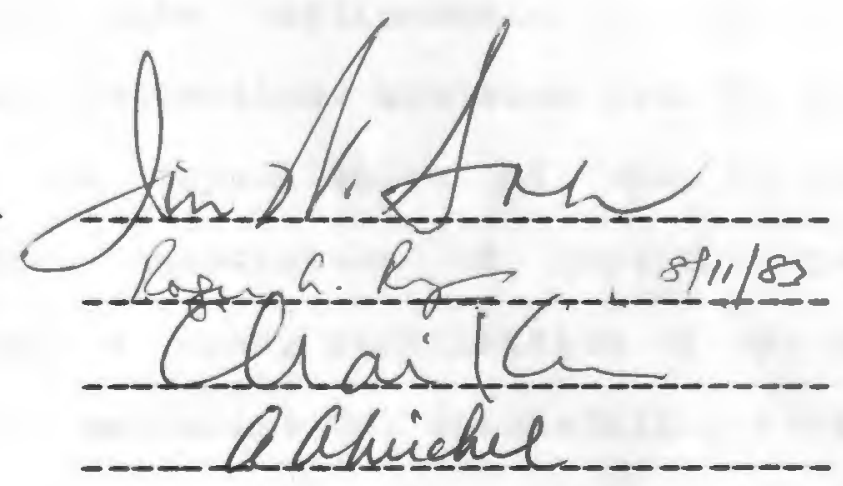

Dean of the Graduate School 
A BS TR ACT

Certain simplifications in the programming language da are suggested. The sinplifications include the renoval of derived types and mininization of intertask comanication in multiconputer like environments to simplify the language design. Suggestions are also made to improve the expressiveness and capabilities of $\Delta$ da by introducing subprogram types, association of implicit queues with entry points of a task. redefinition of the assignment operator and a mechanism for descheduling tasks. These could lead to improve run-time efficiency. exception handling mechanisn an to achieve sinplicity in the language design. 


\section{ACKNOULEDGEE ENT}

I take this opportunity to thank my major professor DI. Jin W. Soh for providing valuable suggestions and encouragement throughout the development of this thesis. I would also like to thank Dr. Lamagna and Dr. Rajan for belping me with those "out of narket" books on Ada and other references. A special thanks goes to ur. Lark Gerhardt of Raytheon corporation a subsIG division of portsmouth, RI for sharing his valuable time with me to point out some problems witb ada. Iast, but not least, I thank my thesis committee for their suggestions and interest in the present vork. 
Table of contents

Chapter One

1., 1

1. 2

1. 3

Chapter two

2. 1

2. 1.1

2. 1.2

2.1. 3

2. 1.4

2. 2

Chapter three

3. 1

3.2

3. 3

3.4

3. 4.1

3. 4.2

3. 4.2 .1

3. 4.2 .2

3. 4.2 .3
Introduction-

Desired features in programming

languages-

Motivation behind the present study-----3

objective of the study- -

Suggestions to simplify Ada-

Derived types--n--n--

Portability of numeric types-- -- - -12

Poor man's strong typing-

Change of representation-- - - - - 14

private types-

Concurrency on multi-computers------18

Improving abstract mechanisms in da--22

Message passing between tasks------22

Redefinition of prinitive operators-- -28

Flexibility in scheduling disciplines--34

Exception handling-

Reasons to provide exceptions----- -37

Requirements to implement exception

mechanism--- - -37

Association of handlers with oferators-38

Default exception handlers------- 38

Various control flows--- - - - - - 39 
page 2

3.4. 3

3. 4.4

1.4. 4.1

3. 4.4 .2

Chapter four

References

Appendix A
Bxception handling nechanism in $1 d a---40$

Suggestions to inprove exception

nechanism in Mda--

Conpile time checking-- -

Implementation of varios control flous -43

Coric Iusian-_- -51

$-53$

Subprogran types-- 
Becent advances in electronics have dranatically shifted the overall cost structure of computer systems from the cost of harduare to the cost of software development. part of the reason is that programing is a labor intensive activity with conplexities far beyond the capabilities of a single programmer. Thus it is not unreasonable to expect programs, with a typical life span of 10 years, being written by a team of people vith several man years of involvenent. This calls for breaking of a conplex problex into independent modules, communication between programmers to know about the assertions each one makes about his module, and finally putting the modules together to obtain a unified 'working' program. Changes in a program, also called maintenance, are inevitable over the span of its life. A study [6] has shown that such maintenance costs exceed the development costs of the original program. The main reasons which contribute to high maintenance costs are as follows:

(1) A turnover in the original staff. Thus a cost is associated with training a new programmer.

(2) The structure of the final program is of little help in understanding how the original problen was decomposed and progranned. This adversely affects the precise understanding of the program. Though informal documentation, through comments, can be provided. it leaves enough room for ambignities and 
misinterpretation.

(3) Changes during the naintenance phase are liable to canse inpairment of the original structure of the prograns thereby making future changes increasingly difficult to introduce.

B J Dijkstra yrote about this software crisis [5]

" As long as there were no machines, progranning was no problen at all; when we had a few weak computers, programing became a mild problen, and now that we have gigantic conputers, programing has becone an egually gigantic problen. In this sense the electronic industry has not solved a single problem, it has only created them, it has created the problen of using its products w

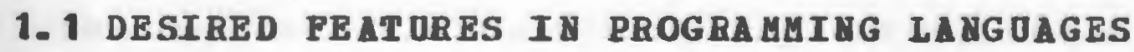

The present day software technology enphasizes the need of progranning languages which

-Facilitate easy uriting and reading of a program.

- Retain the deconpositional structure of the original

froblem into the final progran.

- Provide facilities for developing modules of a conplex problem independently-

- Pacilitate communication among members of a tean working on some global project by providing ways to specify an interface of a module to its external environment without being concerned with its inplenentation details. 
- Provide ways to specify concurrent execution to exploit the availability of cheaper nicroprocessors and supporting hardware components.

- Provide facilities to specify lou level details in a given application to generate efficient code.

Dotivated by these reguirenents, the oS Department of Defense launched a project to design a languge and its support environment to incorporate these to simplify software development. The present thesis is based on the outcome of this massive effort, the language da.

\subsection{MOTIVATION BEHIND THE PRESENT STODY}

There always seems to be a resistance in the softuare community to accepting a new language. No matter how reasonable this resistance may sound, due to the grouing technology and the sinultaneous groyth of the application domain, earlier languages like FORTRAN, PASCAL. PI/I can not be used to meet the new challenge in the right perspective. These languages have been modified over the years, eg. FORTRAM77. Concurrent Pascal to keep up with the application needs but without nuch impact on programing style. These languages, as pointed out earlier also, have several draubacks, which prevent then having any future in the development of complex softuare projects. The language $\mathrm{da}_{\text {, }}$ in the beginning, was designed keefing the reguirements of 
embedded systems [6] in mind but it is powerful and general enough to replace basically all existing higher level languages. To drive the idea home. let us compare the 1 anguage, pascal, ( pointing out PASCAL's draubacks through an exanple) with the. language Ada and see how these problems are resolved in $\mathbf{a d a}$.

1.2. 1 sample problen

a database containing information about enployees. including their nanes, divisions, telephone numbers, and salaries is assumed to be available. The Frogram must produce a data structure containing a sorted list of the employees in a selected division and their telephone numbers.

A typical PASCAL solution may look as follous:

C Defining all the useful types

C for the prograa

type STRI IG = packed array $[1 . .24]$ of CHAR:

C type string is for the name.

C lame can be 24 characters long.

$$
\text { SHORTSTRIUG = packed array [1.-8] of CHAR: }
$$

C type shortstriag is for the name of the division.

C Division name can be eight characters long-

C Information about each enployee is available in

C the records of type EHPRBC.

$$
\text { EMPRBC = 드르or므 }
$$


PHOWE: I HTEGER ;

SALARY : BEAL;

DIVISION: SHORTSTRING:

end:

C Besult is returned in the variable

$c$ of type PHONERBC..

PHON EREC = record

NAUE: STRING:

PHOUE: I HTBGER:

end:

c Declaring program variables.

vax - STAFF: array [1.,100] of BUPREC:

PHOME: array [ 1..100] 으 PHOHEREC;

STAFFSIZE, DIVSIZE, I, J: IXTEGBR;

Q: PHOUEREC;

begin

c size of the division of interest is

c initialized to zero.

DI VSIZE $:=0$;

C In this loop the nanes and phone numbers

C of all the employees belonging to the division

C denoted by HACHDIV are collected in array PHOdE. f을 $I==1$ t으 STAFFSTZE do

if STAFF[I] DIVISION = NBICHDIV then

C BHICHDIV corresponds ta, the division of interest. begin 
PHONES[DIVSIZE ]- BAEE := STAPF[ I ]. WAHE:

PHONBS[DIVSIZE] RHOWE := STAFF[I]-PHONE;

end:

C Mithin these loops the array $P$ HONE is sorted

C with respect to employees names.

for $I:=1$ teo DIVSIZE do

for $J:=I+1$ t으 DIVSIZB do

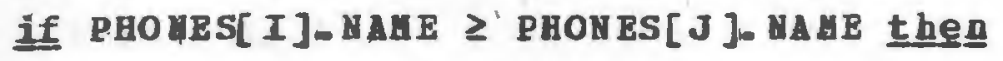

begin

$Q:=\operatorname{PHOVES}[I]$ :

PHONES[I] : = PHONES[ J]:

PAONES[J]:= Q:

end:

end:

The problens with PASCAL (ignoring the aspects of concurrent programning and lov level nanipulations) are

(a) It provides linited support for large programs and is lacking in separate conpilation facilities and block structure other than nested procedures.

(b) There is no support, for the encapsulation of related definitions in such a way that they can be isolated from the remainder of the program.

(c) It does not alloy programmer defined types to accept parameters. If it did then ve could have done with only a single definition for both types STRING and SHORTSTRIMG by passing it a length paraneter in the 
above progran.

(d) It does not provide any information hiding. For example. there is no vay to make the nane of an enployee knoun without alking his salary (a sensitive datua)' also kñoun.

The above example can be programed in a much better way using Ia as follous:

package BuPLOTEE is

type PRI VSTOFF is lipited private:

tyce EuPREC is

recora

MAUE: STRING $(1 .-24)$ :

PHCNES INTEGER:

PRIVPART : PRIVSTURE:

end record:

procedure SETSALARI (DHO: in out BAPREC; SAL:FLOAT):

function GETSALARY (wHO: EUPRBC) return FIOAT:

procedure SETDIV ("WHO: in out EHPREC; DIV: STRIYG(1.-8)):

function GETDIV (DHO: EHPREC) return STRIUG(1.-8):

private

type PRI VSTUFF is

record

SALARY = FLOAT:

DI'ISION : STRING (1...8):

end record:

end EGPLOYEE:

Note that in this package we have been able to encapsulate 
the definition of type EAPREC and its associated operations within the package BHPLOYEB. Sensitive data like salary and division are declared to be private. Thus they can only be accessed through subprograns, wich may check' the user-id before allowing the access, the access being defined in the visible part of the package. The package body may be defined and compiled later but prior to execution. Since the type STRING is parameterized, we do not have to define two separate types for MAME and DIV. The main program is almost identical to the PASCaL program, except for some minor syntax differences, hence not discussed. In brief, the language ada not only supports the capabilities of existing languages, but facilities for separate compilation, top-doun and bottom-up program development, data protection, real time programing among others. It is predicted that ada will doninate the programming activities in late $80 . \mathrm{s}$ and $90^{\circ} \mathrm{s}$. It appears therefore worthwhile and significant to study if na indeed does what it pronises in application programing.

\section{3 OBJECTIVE OF THE STODY}

The design of systems utilizing the complete set of capabilities is quite complex. To date there has not been a single such system even though the syntax of the language were first published in 1980. A major reason for this delay appears to be that the designers of the 
language failed to understand the depth of complexities in its implenentation. In this thesis some of the problens of Ida are identified and some sinplifications are suggested. same level of functionality and expressiveness (Chapter Two).

An attempt is also made to inprove some aspects of da ky introducing new concepts: These concepts add to the expressive power, run-tine efficiency and to the overall capabilities of the language. 
CHAPTER TRO

SOGGESTIONS TO SIUPLIFY ADA

The meaning of 'simplicity' when applied to progranuing languages can be guite deceptive. In the hierarchy of prograning languages, assembly language is conceptually very simple. But writing an average size progran in assenbly language can be guite cumbersome. What assenbly language lacks is expressiveness. $A$ language is expressive if it has a built-in abstract mechanism to siuplify the progranning of a problen at hand e.g. a variable name is an abstraction of a memory location. It can be ade increasingly expressive by adding special-purpose abstraction. Therefore a language can be very simple without being expressive. On the other hand, it can be made very expressive but not so simple to implenent.

The ain of this chapter is to identify and remove those abstractions in ada wose functionality can be realized using other built-in abstractions in the language. This will simplify the language design without any significant loss in its expressiveness and portability. The discussion is linited to two aspects of Ada. Vamely.

(1) Derived Types,

(2) Concurrency on uulticonputers. 
- type in $\Delta$ da can be derived from a parent type such that the derived type inherits some of the operations defined for the parent type including all basic and predefined operators and the domain of the derived type is same as its parent type. A conpiler sees then as two distinct types, interconvertible by explicit type conversions [19]. Here we shall attenpt to shov that this facility is superfluous and the same functionality can be achieved using other features available in the language thus reducing unneccessary conplications in the language design. The follouing is a list describing the conplications introduced in the language design by the derived type definition

(a) Explicit conversion operators have to be made available by the conpiler.

(b) Each basic and predefined operator of the parent type have to be redefined for the derived typei

(c) Certain subprograms that define the operations of the parent. type are to be redefined inplicitly for the derived type in a transitive manner.

(d) Overloaded literals, aggregates, entry, slice, attributes, etc. have to be resolved for the derived and parent types.

Inplicit definitions slow down the compilation process while making the design of compiler more difficult. The Ada language design tean has listed four notivations [13] for the derived type facility as follous: 
(1) achieving portability of programs using numeric types.

(2) Poor man's strong typing

(3) Change of representation: if the derived type $T$ is explicitly given a representation specification (indicating offsets and widths of record fields and other low level details). then conversion between $T$ and its parent type also effects a change of representation.

(4) Bnable the construction of private types.

The following discussion. based on a paper by Hilfinger [13]. will illustrate how to achieve the same level of capabilities without resorting to derived types.

2. 1. 1 PORT ABILITY OF NOABRIC TYPES

The type

type I 4 T is L..O;

is elaborated using a derived type definition as follous: type IATBGER-T YPE is neU PRECEFIABD-INTEGEB-TIPE;

subtype $T$ is INTEGER-TYPE range $\langle>$ INTEGBR-TYPE (L) . . INTEGBR-TYPE (U) :

where IXTEGER-TYPE is an anonynous type and PREDEFINED-INTEGER-TYPE is implicitly selected by the conpiler so as to contain the values $I$ and $J$ (inclusire) thus providing complete portability [19]. A similar elaboration definition holds for the real type. To achieve the same effect, vithout derived types, we can define 
subtrpe INT is INTEGER-TYPE range L..0:

where the programmer has to select INTEGEB-TYPE depending upon the implementation. The point to note here is that only a subset of these subtype definitions need be changed when moring to a new target machine because mast of the defined INTBGBR-TMPE will satisfy the range constraint. The compiler will check this compatibility in relation to the target nachine. Aditional advantages of this approach are

(1) Subtype definitions do not introduce a nev type; thus the compiler does not have to mange too nany types. (2) The management of mathematical packages is simplified. For erample, suppose we want to use two independently compiled generic mathematical packages in a frogran. assume that these packages are made generic in type REAL. This will cause a comunication problen when the results are to be exchanged between these two packages since the type in each package is distinct. The programer has to perform explicit type conversions to exchange the results. A better solution is to define a mathematical package as follows:

package MATHOACTIONS is

function SIM( $x:$ FLOAT) return PLOAT:

function SIM(X:LONG-FLOAT) returin LONG-FLOAT:

end MATE-FUNCTIONS;

In the abore package, function SIN is frovided for 
all possible real types supported by the nachine. The communication problem goes ayay because now nathenatical packages need not be made generic in type RBAL.

\section{1.2 POOR MAN'S STRONG TYPI WG}

The Ada compiler prohibits the mixing of mathematically identical but unrelated data types. This can prove helpful in elininating unintended programming errors. For exanple,

\section{type DOLLARS is ney INTEGER;}

type POONDS is ney I ITEGR;

The conpiler will prohibit nixing of POOHDS with DOLLARS. This strong type checking can't be provided without derived types. On the issue of desirability of such strong type checking in Ada, Hilfinger points out [13]

n This type checking was a side effect of the attempt to achieve the portability of programs rather than to a perceived need to. provide a vay of differentiating arithmetically identical nuneric types"."

Thus it is hardly justified to introduce derived type for this sort of checking.

\section{1.3 CHAMGE OF REPRES BNTATION}

Ada provides a facility for specifying the hardware inplementation of a type through representation clauses. 
at nost one representation clause is allowed for a given type. To illustrate how to achieve the change of representation. consider the following example

tyce 1 is

record

AGE: IN TBGER:

WEIG BT : INT EG BR :

end:

yov using derived type definition we define another type B E is neu A:

and impose the following restriction on the representation of $B$

for B use

record

AGE at $0 * B$ YTE range $0 . .3$;

NEIGHT att $0 * B$ BYE range $4 \ldots 7$ :

end:

Now the declaration

X:A; $\mathbf{Y}: \mathbf{B}$ :

defines two record variables with two different

representations. A change of representaticn can be obtained by a simple assignment statement as follows:

$Y:=B(x):$

Wote that type-mark $B$ is required to effectuate the change of representation. To achieve the same effect without derived types, let us define the type $B$ as

type $B$ is 
record

AGE: IUTBGER;

DEIGHT : I NT EG BR ;

end:

and its representation clause as defined before. The conversion from one representation to another can be achieved by a user defined procedure CONVERT as indicated below

procedure CON VERT CORIGIMAL-REP:A; DESIBED-REP: out B) :

\section{beging}

DESIRED-REP.AGE $==$ ORIGNAL-REP AGE:

DESIBED-REP. HEIGHT := ORIGIWAL-RBP.HBIGHT:

end d COUVERT:

Thus all we need to effectuate a change in representation is to call the procedure COWVRT as follous CON VERT $(X, Y)$ :

\section{1. 4 PRIVATE TYPES}

Private types is a way to allor linited access to a variable of this type thus protecting it fron undesirable/unintended operations. Consider the following package specifications:

package a is

type INT is prirate:

function "+" (U, V: INT) return INT:

private 
type IHT is pen IUTEGEB;

end :

package body a is

function $"+n(0, V:$ IXT) return INT is

begin

returg IMT* (INTEGER(0) + INTEGER (v)) :

endi

end 1 :

The derived type enables a programmer to define a type IITEGER which is distinct from the predefined type INTEGBR syntactically. The same functionality can be achieved without derived types by elaborating the private type definition as

private

type IKT is

recora

\section{X: I WTEGEB :}

end:

and defining the package body as

package body is

function "+" (0,v:IwT) return IuT is

begin

return IUT'( $\left.0_{-} X+\nabla_{-} X\right)$;

end:

end $\mathbf{A}$ : 
Here the record type elaboration of the frivate type behaves exactiy as the previously defined private type as far as the user of this package is concerned.

This demonstrates very convincingly that the introduction of derived types is an unnecessary conplication of the language as the desired functionality can be achieved using existing facilities in the language.

\section{2 CONCURREHCY ON HOLTICOLP OT ERS}

The Ada reference manual states that " tasks can be inplemented on multicomputers, nultiprocessors or with interleaved execution on a single processor." Let us look at the implementation aspects of tasks on multiconputers. i. E. a computer architecture consisting of several different computers without shared nemory. The communication between these conputers is done by sending aessages to each other. Two tasks being executed on different computers in $\mathbf{A}$ da may

(a) not communicate at all with each other:

(b) communicate through global variables only: and. (c) communicate through entry calls and global variables. Inplementation of case (a) is very straight forward but the latter two cases vill reguire much additional comunication overhead. Consider two tasks $A$ and $B$ being executed by different conputers, and operating on the same global variable G. The variable $G$ may reside in the menory of computer A or B or possibly in another computer. 
say C. In the worst case assune that it resides in the renory of computer $C_{\text {. }}$ This inplies that every access to $G$ fron task $A$ or task B vill reguire communication vith conputer C. Such communication protocols will have to be provided at compilation time thus making the language design more complex. Sinilarly vhen global variables are access variables, then again extra commuication overhead vill be required. Note in this case the fointer values will have to indicate which computer's menory they are pointing to Thus the pointer nanagenent will become nore conplex and its size will possibly have to be increased toidentify the computer vhose memory is being pointed to. These inter-computer comanications besides adding to the conplexity of the design, affect the run-time efficiency adversel $y_{-}$

The Ida manual [19] specifies the follouing for the access of global variables by tuo cr more tasks.

" if two tasks read or update a shared variable then neither of them nay assume anything about the order in which other perforns its operations. except at the points where they synchronize. rasks are synchronized at the start and at the end of their rendezvous and at the start and end of their activations*.......

The abore specification can be used to drau the following two conclusions

(i) If, between two synchronization points of a task, a task reads a shared rariable whose type is of the 
scalar or access type, then the variable is not updated by any other task at any time between these two points.

(ii) If, between two synchronization points of a task, a task updates a shared variable whose type is scalar or access, then the variable is neither read nor updated by any other task between these tro points. These conclusions allow an inplementation to keep a local copy of the shared variable in a register or menory of conputer. This mininizes the interconfuter communication as it is required only at the start and at the end of the synchronization points. The problen of niainizing the communication overhead for those tasks that only commuicate through global variables still remains. Note that an indivisible vite or read operation on a shared variable can be provided by a pragna as follows:

p드므르르 SHABRD (sinple-variable-nane):

CAR Hoare [11] avoided this problen in his paper " Comunicating sequential processes" by restricting the inter-task commuication by means of input/output only that is through entry statements only-

There seems to be no nontrivial solution to take care of this problem unless sone very efficient inter-couputer commuication protocol is available. As Gehani [8] points out, the inplenentation of ada on nulticouputers can be simplified by prohibiting task communication via global or access variables or by ensuring that tasks that share data 
by means of global or access variables vili reside on the same computer.

In conclusion, the remoral of derived types and the inposing of the above restriction in inplementing tasks on nuticonputers potentially offer a substantial sinplification in the language design. A little loss of portability and generality of dia seens to be a small price to pay for the sinplicity and efficiency it provides to the inplementer. 


\section{CHAPT ER T HREE}

\section{IMPBOVI HG ABSTRACT AECHANIS US IN ADA}

1da provides a rich set of abstractions to enhance its capabilities for a variety of applications such as systens programning, parallel programing. programming of embedded systems with real-tine constraints and so on- There are situations when these abstractions are too general or too restrictive to satisfy the requirenents of the problen. In this chapter we will concentrate on the following four situations to demonstrate the linitations in ada.

(1) Message passing ketueen tasks

(2) Bedefinition of prinitive operators

(3) Flexibility in scheduling discipline

(4) Exception Bandling

In attenpt will be made to elininate these linitations by suggesting some improvements in the abstraction mechanism. As we shall see later, it will be achieved without making the design of the language any nore complex.

\section{1 heSSAGE PASSIHg BETHEEN TASKS}

The design of systens with 1 da is intended tc serve as a progranming standard for enbedded computer applications (i.e. command, control, commuications, avionics, shipboard applications, etc-). Is a conseguence of its projected applications, the language contains facilities for parallel and real-tine programing in multiprocessor 
and multicomputer environments. Uultiprocessor applications tend to have much more stringent requirements for run-time efficiency than do most applications developed for uniprocessor environment. Hultiprocessor based systems have significant advantages over corentional uniprocessor environments in three distinct areas [26]

(1) Multiprocessor systens are capable of increased, effective throughput because they allow independent tasks within the application to operate in parallel.

(2) untiprocessor systems can be designed to include software reliability structures that exploit the redundancy in hardware to dynamically alter the system configuration in response to hardware failure. Becovery frcm failure is a prine consideration in applications where human lives are involved such as monitoring nuclear plants or controlling war-weapons.

(3) Uultiprocessor systems can be expanded gracefully as the reguirements of the application domain change.

Inong these, run-tine efficiency seems to have favored the design of nutiprocessor systems strongly- For this reason, the parallel control features provided by an inplementation language intended for the use with ultiprocessors nust be designed to allov highly efficient 
interprocess communication and control. In this section. we will analyse the suitability of da for multiprocessor applications in relation to the above requirement. Let us consider a typical application of a unidirectional comunication between PRODUCER and CONSOHER tasks through a BOFF ER task- Task BUFFE can be specified as follows

tasㅗ $B$ OFFER is

entry READ (ㅂ: 으느 HESSAGE):

entry ARITE (U: MESSAGE) :

end BUPFER:

task body EOFFER is

H: constant INTEGER :=101;

type IADEX is IATEGER range 1.-N;

Q: aray (INDEX) of 으 MESSAGES:

FIRST,SECOND: INDEX :=1;

$\underline{100 p}$

select

uhen LAST nod $N+1 /=$ FIRST

accept NRITE (H: in UESSAGE) do

$Q(\operatorname{LAST}$ nod_ $N+1):=4$;

end RITE:

LAST := LAST 끄으 $4+1 ;$

으

when FIRST $/=$ LAST

accept READ (M: out UBSSAGE): 


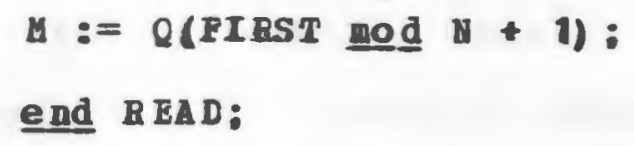

end loop:

end BOFFER;

Now assume that the PRODDCBR task executes the entry call BOFFER-DRITE (SOUE-UESSAGE) :

to initiate the transfer. According to the senantics of the entry call. the PRODOCER task is now blocked until the BUFFBR task is scheduled and conpletes the rendezvous. During this tine the PBODUCER task must wait to te rescheduled when the BOFFBR task completes the rendezvous. Thus, before a PRODUCER is alloved to proceed, two scheduling operations must occur. Sinilarly two nore scheduling operations are required to read a nessage. This implies that a total of four scheduling operations are needed to transnit a single nessage During this time PRODUCĘR or CONSUUER tasks are waiting without doing any useful york.

Since each scheduler interaction nay involve a complete context swap, this implementation of message passing would be prohibitively expensive for nany applications. To give an idea about the severity of the problem, if scheduling interactions are reguired to ensure the mutual exclusion. 
the path through the critical region would reguire typically about 200 instructions there-by reducing the orerall efficiency by an order of nagnitude. If the critical region is sufficiently small, say 10 enstructions, then the price to pay for ensuring mutual exclusion is intolerably high. Further danage to the efficiency of a real time program can result if this program requires freguent assage passing between tasks, wich is generally the case.

In an at tempt to solve the above problem. let us look at how the the tasks are queved at an entry (say E) in a given task. Queves of tasks can be very easily inplemented by reserving a queve pointer cell in the activation record of each task as shown in the following figure.

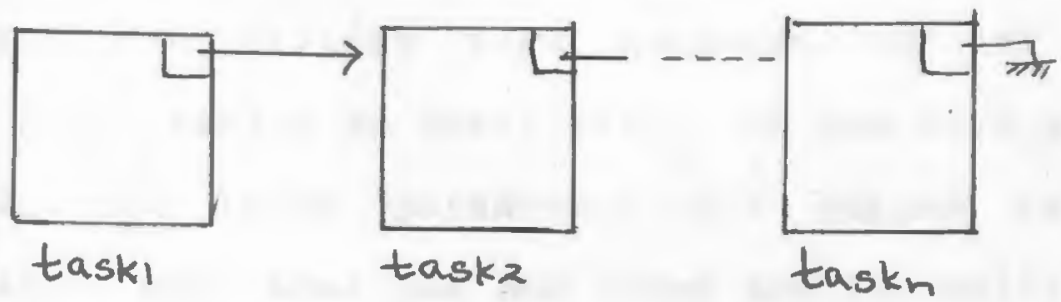

When a task calls entry E, it will be queved as shown, or when the called task executes the accept statement for entry $E$, then the first task (in this case, Task1) will be taken out from the gueue. So basically this queve can be accessed by nore than one task at a given time. The underlying systen for ada nust ensure the indivisible 
access to this queue by each task. Jim Welsh [26] suggested to extend the abstract mechanisa in ada to provide a data queue associated with an entry point. For the sake of simplicity assume the storage for the data queue is statically deternined at conpile time. Is the rechanis Il to provide indivisible access to gueves of tasks already exists, it is very easy to extend this to the data queue without adding to the complexity of language design: The modified BOFFER task can be defined as follows:

task BOFPER is

entry NRITE ((100)) (H: in MESSAGE):

entry READ ( $(100)$ ) (H: out MESSAGE):

end BUFFER:

Without introducing any changes in the body of the task BOFFER. The parameter ((100)) specifies the data queve size. Now for the case of an entry which has only 'in' parameters, the calling task performs one of the two actions when making an entry call. If the data gueue is not full, the input parameters are copied into the preallocated data area for the queue and the calling task is allowed to proceed even if EUFFER task is unable to complete the rendezrous. If the data queve is full then the calling task (PRODOCER) is queued at the appropriate entry (HRITE) as in the conventional approach. The EUFFER task, upon reaching an accept statement (WRITE in this case) performs operations in the following seguence: 
(1) If the associated data queve is enpty then do nothing: otherwise, copy the first data from the associated data queue into the local data area ' $Q$ ' associated uith the task BOFFER.

(2) If, as a part of the same operation, the data queue was previously full, then pick the first task, if ang. vaiting at the entry and copy the associated message in the data queue. At this point the calling task is free to proceed.

A similar mechanism can be used to handle the case of entries which operate in the opposite direction and have only an 'out paraneter. Wote that this inplementation is possible becanse the PRODOCER and CONSU UER tasks have either all 'in' parameters or a11 'out' parameters. This scheme will add to the run-tine effiency by reducing the number of scheduler interactions involved. one interesting obeservation about the approach is that the data queue implementation can be interpreted as a pragma, which a compiler is free to ignore.

3. 2 REDEEI AITION OF PRIMITIVE OPERATORS

One of the nain criticisms of da arises from the fact that it does not allow the redefinition cf prinitive operatiors, most notably the assignment operator. There are cases when redefinition of assignment and equality operators is desired. De will see that these 
redefinitions add to the simplicity of design and expressiveness of lda without affecting its run-time efficiency or the conplexity of the conpiler [13]. To illustrate the point, let us consider operations on varying length string variables. a type pariable-string can be defined as follous:

subtype IXDEX is IATEGER range 0.. IrTEGER'IAST:

type VSTRI HG (GAXLEH: IUDEX) iㅗ

record

POS: IKDE X $:=0$;

VALUE: STRIKG (1-DHAXLEN) :

end:

Following are the desirable operations on the variables of type VSTRING (PI/I provides these)

(a) $\nabla 1:=V_{2}--\operatorname{copy}$ a string variable

(b) v1:= "IRITI ALIZE TO STRIKG"

(c) $\nabla 1:=\nabla 1 \&$ "APEND";

sccording to the definition of assignnent operator in current Ada [19]. statement (a) will be legal if and only if $\nabla 1$ and $\nabla 2$ have the same naximum length. What is reguired is the desirable condition for the legality of the operation to be

leagth (v2) $\leq$ length(v1)

Statement (b) is not legal at all since the itens to the left and right of the assignment operator are of two different types.

statement (C) will be legal only if the variable returned 
after concatenation satisfies the criterion mentioned in (a).

The desired effect can be achieved by defining a procedure such as

procedure SET(OBJECT: in out VSTRIYG: VALOE: STRING):

- - body of the procedure

end SET:

which converts a string literal to a variable of type VSTRING.

But consider the following case:

procedure RANDOM (Z=VSTRING) is

- - - body of the procedure

end BANDOH:

As statements of type (b) are illegal, a call to procedure RA XDOH

RAMDOH ("SOEE STRING") :

uill be illegal because it involves an assignnent of a string literal to a variable of type VSTRIMG. The vay to get around this problem is to call procedure SET to convert the literal string to the variable of type VSTRIMG and then to call procedure RANDOB. Clearly it is an unnecessary complication in calling the procedure.

Things can be sinplified if redefinition of the the assignnent operator is allowed. A natural consequence of this will be that the equality operator "=" vill also becone an ordinary relational operator. The following is 
a list of najor changes, suggested by Hilfinger [13]. to be done to introduce $":="$ operator in the language.

(1)

Remove the linited keyword and instead nake all private types "linited" in the sense that they do not autonatically export a $"==n$ or $n=n$ operator.

(2)

Add ":=n as a definable binary operator and make the operator "=" an ordinary relational operator in all respects.

(3)

Define all operators $n:=", n=n$, and $n /=n$

inplicitly on all scalar, access and composite types as provided in current ada obviously assignment on conposite types uill be defined componen t-uise.

(4)

Define a invocation of a $":="$ operator to be type valid if two actuals have the sane types as their corresponding formals. An invocation of any other subprogran is type valid if each actual paraneter has the sane type as the corresponding formal or is assignment conpatible with the formal.

Onconstrained formal parameters inher it any discrininant constraints as in current ada except in the case where an unconstrained 'in' paraneter does not have the same type as its corresponding actual. (We have seen this in 
relation to procedure RAwDou). In this case. the discriminants of the fornal are set by the assignment operator.

The following package can be defined, using := operator definitions, as a library unit to implement type VSTRIYG package STRI WG is

type VSTRI WG (HAXIEA:IMDEX) is_prizate:

- the domain of VSTRI NG(W) is all

- strings with length $\leq$ w

procedure ":=" (LHS: out VSTRING; S:STRING):

procedure ":=" (X: out VSTRING; Y: VSTRING):

--copies $Y$ into $X$ iff the string in $Y$

-is in the domin of $x$

fuuㅡ노으 $"="(X, Y: V S T R I G)$ return BOOLEAd;

funcction " $\&$ " ( $x, y$ : VSTRIHG) return VSTRIHG:

private

type VSTRI WG (UAXLEW:IWDEX) îㅗㅗ

record

POS: IHDEX : =0;

VALOE: STRI HG (1.. VIAXLEW) ;

end record:

end STRING;

How the statenents (a). (b). and (c) are legal if the string in $\mathrm{RHS}$ is in the domain of the string in LHS. And also the procedure BANDOB can be activated without anI conplications. 
The redefinition of ":=" operator can also inprove the expressiveness when dealing with literals. suppose ve wish to represent a set of integers. In current a da one can urite

subtype INT is INTEGER range 1.-20:

type SBT-OF-IMT is array (IHT) of BOOLEAN;

How a set of integers $(1,7,10,13)$ can be denoted as SBT-OF-IUT' $(1 / 7 / 10 / 13 \Rightarrow$ IR OE 。 otherS $\Rightarrow$ FALSE $)$ :

A better notation yould be

type SBT-LITERAL is array (INTBGBR range - ) 오 IAT;

procedure ":=" (LHS: ont SET-OF-IAT; RHS:SET-LITERAL) is begin

IHS : = SBT-OF-INT' ( otherS $\Rightarrow$ FALSE) :

fo도 I in RHS'range loop

LHS (I) : = TR OE;

end loop:

end.

This enables us to represent set $(1,7,10,13)$ as

$$
\mathrm{I}=\mathrm{SET}-\mathrm{OP}-\mathrm{IHT}:=(1,7,10,13) \text { : }
$$

This representation is guite expressive and conceptually siuple. A redefinition of the assignnent operator poses some validation problens. To illustrate the point. consider the following case:

procedure ":=" (LBS: Out INTEGER: RHS: INTEGER) ' is begin

ST AN DARD." = =" (LBS, 0) : 
end:

you this uill aluays assign a integer value $00^{\prime}$ to LuS thus the normal meaning of assignment operator has been breached. This will certainly make the programs more difficult to understand. The arguenent for allowing this type of problen is that the definition of ":=" is a subprogram like any other and thus should be tested for the legality of the operation.

\section{3 FLBXIBILITY IN SCBEDOLIVG DISCIPLINE}

one area in wich ada has been criticized widely is that it does not provide adequate control over scheduling policy. [26]. To get the flavor of the problen, suppose Ada is chosen as the implementation language for the design and development of a time-sharing systen for a multiprocessor architecture. Individual user processes can be represented as independent tasks in the tine-sharing structure. In a typical tine-sharing systen. each user process is allowed execute for a linited time slot (quantum) in one stretch. If this slot is exceeded, the process is forcibly descheduled and other waiting processes are allowed to execute: The perfornance of a tine-sharing system is quite sensitive to the size and dynanic behaviour of this quantun limit and it is inportant to be able to adjust this to conform to the loading demands. 
In 1da. there is no apparent vay to specify a run-time linit for a task nor is it fossible for one task to control the scheduling or descheduling of the other tasks. 1ccording to the present semantics in sa, two indirect approaches are possible for scheduling the tasks

(1) Design a scheduler wich operates cooperatively in the sense that task thenselves participate in scheduling decisions. In this case, each task would ke required to check periodically its accumulated run-tine and disniss itself by executing a delay statement.

(2) Provide interrupt entries in each task. The scheduler will generate a software interrupt for the associated entry of the task to be deallocated. This task can deschedule itself by executing a delay statenent within its corresponding entry-

The first approach can be rejected outright because it reguires the compiler to perfora complex path analysis and to assemble the code to poll the scheduler at frequent intervals.

The second alternative nay seem acceptable but it is an implementation dependent feature. Thus portability is sacrificed and noreover the readability of the progran is 
nade difficult.

Jil Welsh [26] proposed solving this potential problen by introducing a language primitive

\section{deschedule T:}

The effect of this statement will be to deschedule the task pointed to by the task object $T$, thus allowing other waiting tasks to execute. A second alternative, according to the author, can be to provide a provisicn in ada to alter the priority of the tasks dymanically. In current Ida the priority of a task is fixed at the compile time. As the run-tine system schedules the tasks with higher priority first, the desired effect can be achieved,

\section{4 EXCEPTIOU HAEDLING}

Iraditionally exceptions are the error conditions that arise during frogran execution when certain operations are inroked. Bringing an exception condition to an invoker's attention is called raising an exception. The invoker responds to this exceptional condition through a corresponding handler a few examples of exceptions are overflow exception, underflov exception, and end of file exception. The trend in programing languages these days is to be able to raise exceptions not just for error conditions. This fleribility, as we shall see soon, leads to simpler and nore efficient programs. 
3.4. 1 REASOUS TO PROVIDE EXCEPTICUS

The win reasons, as specified by Goodenough [9]. to provide exception handing facilities in a given language are

(1) To pernit dealing with an operation's infending failure

ie. range failures and domain failures.

(2) To pernit an invoker to monitor an operation.

To illustrate what we nean by monitoring an operation, consider a recursive subprogran for searching for an item through a data structure, say, a binary tree. Bach time an ite is found, an exception is raised identifying the iten. The invoker of this subprogra can decide whether to get the next item or not. If so, he resumes the subprogram execution othervise it is terminated. This can be particularly economical if the subprogram's state is preserved by the handler. Thus intermediate results can be ade available without unwinding the recursion. This example reinforces the point made earlier in this section that exceptions are not connected with error conditions on1y.

3. 4. 2 REQUIREE ENTS TO IMPLBA ENT RXCEPTION MECHANISU

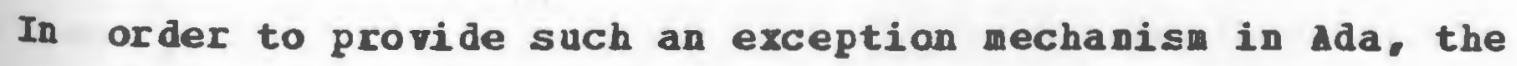
language should be able to

(1) associate handlers with invocation of operators.

(2) support default exception handling.

(3) realize various control flows during the execution of exceptions. 
In the following sections. we will illustrate the desirability of these reguirenents through examples. Interested readers can refer to Goodenough [9] for inplementation aspects. We will also cover the exception bandling as it exists in current ada [19] and try to identify its linitation and suggest some improvements.

\section{4-2. 1 ASSOCI ATION OF HANDLERS MITH OPERATORS}

$\Delta$ handler is associated vith the point of activation of an operation. which can be either a subprogram or system defined operator, i.e.. an arithemetic, boolean or relational operator. This inplies that different handlers can be associated with a given operation at different points of activation. A feu problens that can arise in raising an exception are

(1) Associating a handler with a yrong activation point.

(2) Associating a handler with a wrong exception. This is possible when an operation is allowed to raise nore than one exception.

(3) Forgetting that an operation can raise an exception thus not providing a handler.

These problem can be tackled by letting the compiler detect these.

3. 4. 2. 2 DEFA ULT BXCEPIION HAWDLEBS

It is not guite often that the invoker of an operation uants to associate a different handler vith each activation point. 
Thus it is convenient to be able to specify a default handler, which will be executed unless specifically orerridden. The exceptions which have default handlers are called default exceptions. The folloving are the desirable requirenents in associating an default handler with a exception

(a) Default exceptions should be declared to be so. Thus the invoker of the operator can decide if he/she yants to override it.

(b) It should be possible to specify default bandlers for programer defined operations.

(c) Programmer defined and systen defined default handlers should be treated unifornly.

(d) It should be possible to invoke default handlers explicitly as well as inplicitly. This will provide a flexible control, both botton-up and top-down, in exception handling.

3.4. 2 - 3 VARIOUS COHTBOL FLOHS

Different types of control flous are reguired to deal with different exception raising situations. He can visualize the following three possibilities of control transfer after the execution of an handler

(a) Terminate the execution of the exceftion raising operation and transfer control to the invoker. This type of situation can occur, for example, in overflow exception vile performing some arithretic operation. 
Ada provides this.

(b) Resumption of the operation after the handler has completed its execution. This kind of situation can arise. for exanple. in reading a bad tape. If the read data has some parity error then it is nct uncommon to reactivate the read command from within the handler.

(c) Leaving the decision of termination or resunption of an operation to the discretion of the handler. In this case, before terninating the operation some clean-up actions such as closing all files have to be perforned. For a justification of this type of situation. consider a situation where the tape reading operation is to be terminated after fey trials because of parity errors.

\section{4.3 EXCEPTION HANDING MECHANISH IN ADA}

The author feels that the exception handing nechanis in Ida is a very sinplified version of the above reguirenents and can be used only for a subset of all possible situations for which exceptions are desired. In brief it fails to satisfy the following reguirements

(1) It does not provide any conpile tine checking to deternine if an exception has been provided with the corresponding handler.

(2) It has no provisions to define default exception for the user defined operations. One can argue that for a exception raised by a subprogran we can define a 
default handler in the body of the subprogran. The problem with this is that the default handler can not be overridden by the invoker. This defeats the basic purpose of providing user defined default exception handlers. This treatment of programmer defined default handlers is different fron the language defined defant handlers such as CONSTRAINT-ERBOR, NOUERIC-ERROR etc. which can be overridden.

(3) It provides only one type of control flow, that is termination of exception raising operation. It is, in other vords, a "controlled goto" passing no infornation (aside fron the validity of the exception) to the handler from the statement that raises the exception and allowing no return to that statement. Ichbiah [14] provides a convincing argument by giving the exanple of reading a tape. In case of read errors, the tape is read again up to 10 times before giving uf.

for I iㅡ $1 . .10$ 10op

begin.

BEAD-TAP B (BLOCK) :

exit:

exception

when TAPE-ERROR $\Rightarrow$

if $I=10$ then

raise TAPE-PAOLT:

else 
BACK-S PACB:

\section{endifi:}

end:

this seeas to have eliminated the problen. The above approach nay not be very convenient if the tape reading operation is to be provided at a number of places in a progran because the whole structure has to be repeated. One can argue in favor of providing the tape reading operation as a subprogram with a corresponding hander associated to its body to eliminate the problem. But then it is unreasonable to provide a subroutine for every operation that can raise an exception since exception conditions occur but rarely- such a approach vill affect the run-time efficiency adverse1y.

3. 4. 4 SUGG BSTIONS TO IMPROVE THE EXCEPTION EECHANISA IN ADA In this section an attenpt will be made to iaprove the exception handing nechanisa in ada in the light of the above three requirements. In accordance with the objective of this thesis. we will achieve this without introducing nuch complexity in the language design and ith little changes in its syntax.

\subsubsection{COMPILE TIE CHECKIMG}

The exception handling syntax in da avoids the first two problems mentioned in section [3.4.2.1] by associating a naned handler with the program unit in which exception 
raising operation is invoked. According to the author the third problen can be solved by reguiring the explicit declaration of all exceptions an operation can raise and their static association with corresponding handlers. For example ve can have a subprogran declaration of the following form in da

procedure EXAHPLE (fornal parans) [ BXCEP-A: exception type] is

-exception type refers to three different control flous

- discussed earlier.

- EXCBP-A refers to the exception raised by the

- execution of this procedure.

- local declarations

begin

- subprogram body

endi:

The conpiler is noy in a position to check if the hander is provided in the body of invoker and warn the programmer otherwise.

\section{4. 4. 2 IUPLEHENTATION OF VARIOUS CONTROL FLONS}

One of the attractive extensions of Ada can be the introduction of the subprogram type. The surprogran type, as we shall see later, enables us to achieve the desired control flaw in exception handing besides providing ease of programing. one may be led to believe that this vill introduce considerable complexity in the language design but 
this is not so, $\Delta d a$, in its present forn, has a good deal of complexity already built into its generic mechanism to provide a static version of subprogran values. Thus it stands to reason that such a facility can be introduced without making the design of the language any more complex. To attack the problen neaningfully. we will be conbining present exception handling mechanisw with the new technique to provide all three types of control flows in exception handling. The changes to be wade in the language to introduce subprogram types are given in appendix. 1 .

Returning, to control flow issue in exception handling, consider the handling of an exception in the folloving example

procedure mIN is

BRROR: exceeption:

procedure EXCEPTION-RAIS ER is

beging

Statement-1;

raise ERROR;

Statement-2:

endi

begin

Stat emen $t-3$;

EXCEPTION-RAISER: - procedure call

Statement-4;

exception

uhen $\mathrm{ERROR} \Rightarrow$ Statement-5; 


\section{end:}

According to the current ada, statements vill be executed in the following sequence if the exception condition ERBOB is raised.

Statement-3, State ment-1, Statement-5, Statement-4

Thus execution of statement- 2 has been skipped, whereas we would. like the control to return to procedure BXCEPTION-RAISIR fron the handler. In this case the execution sequence will be

statement-3, statement-1, Statement-5, statement-2 and St atement- 4

To achieve this effect Hilfinger suggested [13] defining a package condrIon as follous

\section{generic package CONDITIOI is}

subtype HAIDLER-TYPE is procedure: -- procedure type subtype BODI-TYPE is_procedure: -- procedure type crocededure SIGWAL;

- paraneter less procedure. Invokes dynamically

- innermost handler established by procedure BUABLE

- Has no effect if there is no handler

FrOCeduIC ENABLE (BODYPART: BODY-TYPB;HANDLER:

HA IDLER-TIPE) ;

- It establishes the handler with the body

- and then executes the body

end CONITION; 
rote that an instantiation of cowDIrIox may not be shared among multiple tasks because of the global variable in the package body. The body of package COUDITIOU can be defined as follous

package body CONDITION is

subt rpe FRAME-TYPE is procedure:

CURRBHTFBAHE: FRAUE-TYPE := beging nul11; endi

- this defines the defualt action for CORRENTFRAMR procedure EHABLE(BODY PART:BODY-TYPE; HANDLER:HAWDLER-T YPE) is

LAST FRAKE: constant FRAG B-TYPE :=CURREATRRAGB;

procedure NGIFBABE is

beqin

CURBENTFRAME : = LASTFRAUB; -- assign dent of subpr. -variables

HANDLER; - - execution of procedure HANDLER CORR ERTFRAUE : = NERFRAUE: exception - note exception OTHERS vill be raised - when some exception is raised within - handler and we vant to terminate

others 7 CORREATPRALE := NEUFRAUE:

end NEWFRAGE:

begin

CORREUTFRAHE : = NEHFRAME; - establish handler BODYPART: -- execution of the body 
CURR EXTFRAHE : = IASTFRALE:

exception -- make sure frame pointer is restored

others $\Rightarrow$ C ORRENTPRAHE $:=$ IASTFBAGE:

end ENABLE:

procedure SIGNAI is

begin

CURR ENTFRAHE: - execution of current handler

end:

end Condriox:

once these packages are defined, associating an exception with a handler is very straight forward process. Bxception ERBOR vill be defined by instantiating the package COMDITIOH. Let us associate this exception vith the program yAIN discussed earlier.

package BRBOR is neu CONDITION:

procedure EXCEPTIOH-RAISER is

begin

Statement-1:

ERROR.SIGNAL: -- activating SIGNAL procedure in ERBOR statement-2:

end:

procedure waIr is

kegin

ERROR. ENABLE / begin -- calling procedure 


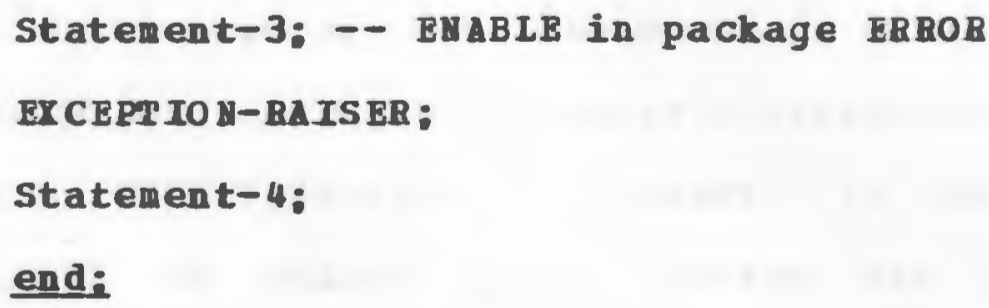

end:

lote that the original main program body and the associated handler are passed to the procedure BMABLE as actual parameters. Let us trace hou the exception ERROR will be handled using the abore approach.

The erecution starts with a call to procedure EIABLE. Declaration LASTFRAE is elaborated and it is initializea to procedure value

\section{begin nu11: end:}

After the elaboration of declarations of procedure EMABIB. the execution of first statement assigns a value beqin

CURB ENTF RAHE : = LASTFRAMB:

Statement-5:

CORRENTFRAHE := - UERFBAHE:

exception

others $\Rightarrow$ CORRENTFRAHE := NEUPRAEE;

end:

to variable CORRENTFRAEE.

Execution of BODYPART procedure witbin the body of procedure 
BNABLE implies the execution of statenent-3, then a call to procedure EXCEPTIOH-BAISER, and finally statement-4. Within the procedure EXCEPTIOH-RAISER statement-1 is executed and exception ERROR is raised by activating the procedure SIGHAL, which executes the procedure CORREMPBAHB. Thus statement-5 is executed and control is returned back to procedure EXCEPTION-BAISER. Note this nethod is, recursive so the nesting can be as deep as permitted by the stack size constraint.

To resolve the third and the final control flow issue, that is. making the resumption of the exception raising operation conditional. the author suggests the folloving

Suppose in the procedure EXCBPIIOH-RAISER we wish to terminate its execution if a certain condition is net in the handler. To achieve this the variable HANDLER can be modified as

\section{declare}

BXIT-EXCBP: exception:

begin

Statement-5;

if (condition) then raise BXIT-EXCEP:

end:

and the procedure MEWFBAE will be modified as procedure UEDPRABE is

begin

CURRENTPRAGE := LASTPRAHB: 
BA NDLER;

CURRENTFRAGE : = MERFRAGE:

exception

others = CORRE UTFRAME := UELFRAUE;

raise: -- raises the exception again

end:

So the exception BXIT-EXCEP will be raised again in procedure EXEPTIOR-RAISER. Wow some cleanup operation, if desired, can be provided within the procedure EXCEPIIOU-RAISER and then the control will be transfered to the main progran.

In sumary, the author would like to enphasize again that the Ada exception mechanism can be improved, with very little changes in the language design, to provide

(1) compile time checking of association of exceptions with corresponding handlers.

(2) flexible control flow.

However, default exception handling still renains an issue to be resolved. 
CHAPTER FOUR

CONCLUSION

In this thesis, the following three questions were raised

(1) Why is a language as complex as ada desirable for programing?

(2) Hov can the design of ada be sinplified without compromising its pouer?

(3) Hoy can the capabilities and expressive fover of ada be improved without affecting the complerity of its design significantly.

We answered these guestions in sequence by

(1) 'shouing the superiority of the abstract mechanisms in Ada over PASCAL.

(2) suggesting some sinplifications in Ada. In particular. we enphasized on

(a) removal of derived types since their functionality can be achieved using existing features in the language thus sinflifying the inplementation of the language.

(b) restricting the shared variables and tasks sharing them to reside on the same couputer oin a 
multiconputer architecture. This sinplified the design of the conpiler by eliminating the generation of comunication protocols and thereby inproving the run-tine efficiency-

(3) introducing new abstractions in the language. In particular, we saw that

(a) the unidirectional message communication between tasks can be inplemented more efficiently by providing a inplicit buffer with each entry point.

(b) redefinition of some prinitive operators such as the assignment operator can make the language more expressive and functional.

(c) inplementation of an abstract "deschedule" would facilitate the design of tine-sharing environments.

(d) subprogram types enabled us to implement the exception handling in a very flexible vay.

The author yould be urong to clain that these are the only problems with ada and these are the only solutions. The inplication of the study is that there is lot of room for improvements in ada and it can be achieved without changing the present Ada's design significantly. 
REF ERENCES

[1] Barnes, JGP, Programmingin da. International Computer Science Series, 1982

[2] Brinch-Hansen, P.. The Architecture_of Concurrentent Programs, Prentice-Hall Inc., Englewood Cliffs, New Jersey 07632,1973

[3] Brinch-Bansen, P., operating systems Principles. Prentice-Hall Inc.. Englewood Cliffs, New Jersey 07632, 1973

[4] Brinch-Hansen, P., Distributed Processes: A Concurrent Programing Concept'. Communications of the AC 4 , Vol. 21, Number 11, pp 934-941, Nov 1978

[5] Dijkstra, EH, 'The Humble Programner', Turing Award Lecture, Communications of the ACH, Vol, 15, Number 10, Oct 1972

[6] Downes, D. A., Goldsack S. J., Programming Emkedded Systers Hith Ada, Prentichall International, Inc., 1982

[7] Gehani, H., Ada An Adranced Introduction. Prentice-Hall, Inc., Englewood Cliffs, New Jersey 07632. 1982

[8] Gehani, v.. 'Concurrency in Ada and tulticomputers', Computer Languages, 77 , No.1, 1982

[9] Goodenough, John B., 'Exception Handling: Issues and a proposed notation', Communications of the ACH, Vol.18, Number 12, pp 683-696, December 1975 
[10] Goodenough. John B.. The Ada Compiler Validation Capability . IEEE Computer, pp 57-64. June 1981

[11] Hoare, Car, Communicating Sequential Processes". Communications of the ACH, Vol. 21, Number 8, pp 666-676, August 1978

[12] Hilfinger, Paul N.. 'simulation of Procedure Variabies osing Ada Tasks". IEEE Transactions on Software Engineer ing, Vol. SE-9, No., 1. January 1983, fp 13-15

[13] Hilfinger, Paul N.. 'Abstract Mechanisms and Language Design . Ph.D. Thesis, Department of computer science. Carnegie-Hellon Oniversity. June 1981

[14] Ichbiah, J., View-Graphs for Jeans Ichbiah's Presentation in 'Proceedings of the Ada Debut". Defense Advanced Research Project Agency, Arlington, Va 22209. Se ft. 1980

[15] Leblanc, J. Bichard, Goda J. John, Ada and Software Development Support: A New Concept in Ianguage Design". IEEE Computer, Hay 1982, pp 75-83

[16] Mben Ari.. 'Principles of Concurrent Programming'. Prentice-Ball International. Inc.. 1982

[17] Nassi, R. Isaac, that is Ada* IEEE Computer, pp 17-24, June 1981

[18] Pyle, I, C., The Ada Programming Languague. Prentice-Hall International. Inc.. 1982

[19] Reference Manual for the Ada Programming language, Honeyuell. Systems \& Besearch Center January 1983

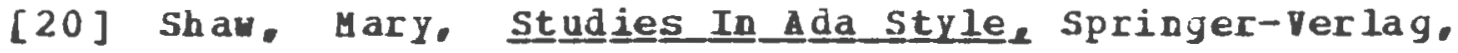


1981

[21] Shaw, Mary. The Impact of Abstracticn Concerns on Modern Programing Language', Proceedings of the IEEE. vol.68 Number 9, pp 1119-1130, September 1980

[22] Singer, Andrey, Ledgard F. H, 'Scaling Down Ada (or towards standard Ada)', Vol. 25, Number 2, pp 121-124, Fetruary 1982

[23] Stenning, Vic 'The Ada Environment: A Perspective' IEEE Computer, pp 26-36, June 1981

[24] Hegner, Peter, 'Self Assessment procedure vIII', Communications of the $\mathrm{ACM}$, Vol 24, Number 10, pp 647-676, October 1981

[25] Wegner, Peter, programming With Ada: An Introduction By Heans of Graduate Englewood Cliffs, New Jersey 07632,1980

[26] Welsh, Jim, and Lister, Andrew, 'A Com rarative study of Task Communications in da', Software-Practice and Experience, Vol. 11, pp 257-290, 1981 
1. The syntax for type mark is changed to

type_mark :: = type_name | cubtype_name / subprogram bypo

2. A subprogram_typo is ecsentially a subprogram epecification, slightly modifled:

aubprogram_type:: :

procoduro [ formal_part]

[ function [ formal_part] roturn subtype_indicadion

3. The operation ": = " is defined implicitly on each functional type, but " = "is not. The effect of the assignment is to make the assigned-to variable refer to the subprogram value of the right operand, but with parameter names and default values as given for the declaration of the left operand. This same replacement of. parameter names and delault values occurs to a subprogram value returned as the result of a function call.

4. A named constant of a subprogram type may be deferred, just as can a constant - of a private type ${ }^{33}$. A complete definition must appear later in the same declarative part (where, for this purpose, the body and private part of a package are considered to be in the same declarative part as the visible part).

6. The literals of a subprogram type are unlabeled blocks:

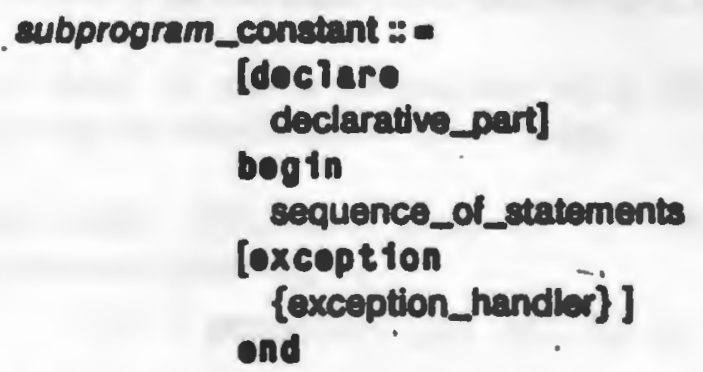

The same block may designate subprograms of several different subprogram types. The type must be determined from surrounding context, without reference to the text of the literal. Any free variables in the subprogram constant are bound in the context in which the constant is elaborated (1.e., not at the point the subprogram denoted is eventually called). Note that the rules stated so far combine with existing parts of the language to provide fully qualified subprogram constants (what a Lisp programmer would call lambda expressions), as in

function ( $x$ : - INTEGER) roturn INTEGER' (bogin roturn $x+1$; and) . which denotes the successor function on the type INTEGER.

6. The decteration 
procoduro Identtpter [ Pormel_part ] te

$\log 10$ doclerative_part

and [ distgnator ]:

ben errarnato bon of .

1denttfior: constent procedure [ formal part ] :doclare

doclarativedpart

$\log$ in

and [ dostgnator ]:

and menom tor bunctions

7. Two hetences of eubprogram_type denots the came type if the exquence of cubtypes of the formal parts (in order) ere painwes identical, and the retum ivpea.

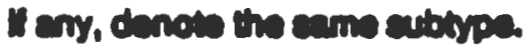

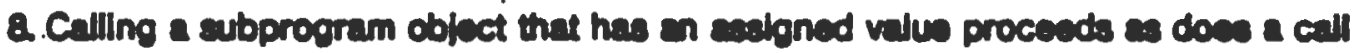
in current Ada. Calling a subprogram object without a dofined velus raises an exception (UNDEF INED_SUBPROGRAM). As in current Ada, names of abprogrem objects may be overloeded and realved by contuat.

Q It is llegal to call a subprogram value when en object referenced in that abprogran value hes been da-allocatied.

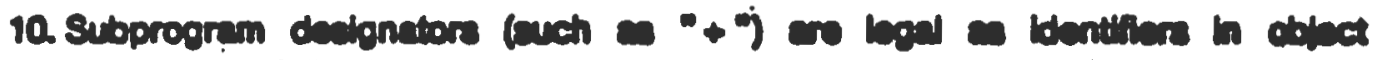
coclarations (cllowing, eqn,

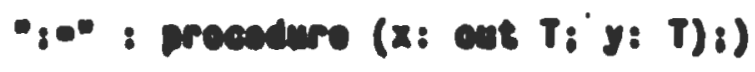

